\title{
Physical and chemical study of lattice kaolinites and their interaction with orthophosphate
}

\author{
MARCONDES SILVA E SILVA, ANDERSON S. LAGES and GENILSON P. SANTANA
}

Universidade Federal do Amazonas, Instituto de Ciências Exatas, Departamento de Química, Campus Artur

Virgilio Filho, Setor Norte, Av. Gal. Rodrigo Octávio, 6200, Coroado I, 69077-000 Manaus, AM, Brazil

Manuscript received on September 12, 2016; accepted for publication on March 27, 2017

\begin{abstract}
This study covers the evaluation of the structure and the capacity in adsorbing orthophosphate ions of kaolinites collected from sampling sites in Manaus (Brazil). The kaolinites were obtained using physical fractioning (sieving/siphoning) techniques and chemical treatment with $\mathrm{HCl}, \mathrm{H}_{2} \mathrm{SO}_{4}, \mathrm{H}_{2} \mathrm{O}_{2}$ and $\mathrm{KCl}$. The investigation of the kaolinite lattices involved the Hinckley and Plançon indexes determined from X-ray diffraction data, Fourier transformed infrared spectroscopy, scanning electron microscopy and Mössbauer spectroscopy. The absorption capacity of orthophosphate ions was calculated by Freundlich and Langergren isotherms. A transitional state was observed in the crystallographic structure from kaolinites because of the isomorphic substitution of $\mathrm{Al}^{3+}$ by $\mathrm{Fe}^{3+}$. This isomorphic substitution occurs accompanied by the optical pleochroism behavior, but it also reduces the mean particle sizes and increases the number of structural defects and magnetic properties of these kaolinites. Mössbauer spectroscopy showed that the substituting $\mathrm{Fe}^{3+}$ preferentially occupies octahedral sites. In the kaolinite lattices there are different octahedral sites of Al bounded by cis- $\mathrm{OH}-\mathrm{Fe}^{3+}$ and trans-OH-Fe ${ }^{3+}$ octahedral sites. The kaolinite from the Kaol sample has a higher number of $c i s-\mathrm{OH}-\mathrm{Fe}^{3+}$ from octahedral sites and is able to adsorb higher contents of orthophosphate ions than those from samples Kao2 and Kao3.
\end{abstract}

Key words: Freundlich, isomorphic substitution, Langergren, Manaus, Mössbauer.

\section{INTRODUCTION}

Kaolinite, a clay mineral formed by octahedral and tetrahedral sites $(1: 1)$, is the mineral that is most found in soil and sediment, mainly in humid tropical regions (Corrêa et al. 2008). This clay mineral is a typical 1:1-type phyllosilicate with the chemical composition $\mathrm{Al}_{2} \mathrm{Si}_{2} \mathrm{O}_{5}(\mathrm{OH})_{4}$. Its surface comprises aluminol groups $(\equiv \mathrm{Al}-\mathrm{OH})$ situated at the edges and the hydroxyl-terminated planes of

Correspondence to: Genilson Pereira Santana

E-mail: gsantana@ufam.edu.br the clay lamellae (Wei et al. 2014). On its basal surface there are permanent negative charges that are responsible for sorption of cations'(Tombácz et al. 2004) and silanol ( $(\mathrm{SiOH})$ linked to the aluminol groups through hydrogen atom (Rehim et al. 2010).

Anion exchange capacity (AEC) occuring on the edges of the aluminosilicate sand layer is $\mathrm{pH}$ dependent. Kaolinite AEC increases with decreasing pH but never $>2.00 \mathrm{cmol} \mathrm{kg}^{-1}$ (Dixon 1989). On its silicate layer, kaolinite notably absorbs phosphates. When linked on edge, the phosphates increases the 
reactivity of the kaolinite (Cui and Weng 2013). The $\mathrm{pH}$ value has great influence on the capacity adsorption of ions by kaolinite: i) $\mathrm{pH}<4$.0-adsorbs anions, ii) $\mathrm{pH} \sim 4.0$ is $\mathrm{PCZ}$ of the kaolinite it does not adsorb ions and iii) $\mathrm{pH}>4.0$ adsorbs cations (Khawmee et al. 2013). Specifically, the adsorption of phosphate occurs in pH 3.0-5.0 (Kamiyango et al. 2009) Malawi, has revealed high phosphate levels ranging from 0.63 to $5.50 \mathrm{mg} / \mathrm{L}$. These phosphate levels would stimulate excessive growth of plants and toxic cyanobacteria in stagnant receiving water bodies hence posing a threat to aquatic life and water quality. Phosphate removal by kaolinite obtained from Linthipe, Malawi, was investigated as a function of $\mathrm{pH}$, contact time, clay dosage, competing ions and initial phosphate concentration by means of jar tests. Phosphate uptake was $\mathrm{pH}$ dependent with adsorption mechanisms on kaolinite and iron oxide surfaces dominant generally below pH 7 and precipitation by calcium ions dominant above $\mathrm{pH}$ 7. Maximum phosphate removal occurred at high $\mathrm{pH}$ values of 11.22 (97.1\% Obviously, the presence of substituents alters the particle size and crystallinity and consequently the ionic adsorption capacity of the kaolinite (Balan et al. 2000).

Since phosphorus is one of the essential elements required for plant growth kaolinite and its modified forms provide an important control over the availability of this nutrient to the soil solution. Phosphate adsorption onto minerals is an important process that significantly affects the mobility and bioavailability of phosphorus in natural environments. Furthermore, the kinetics and thermodynamics studies from the adsorption process provide important outcomes on available phosphorus. Previous researchers have reported numerous kinetic models used to describe sorption processes. These include first-order, and secondorder reversible ones, and first-order and secondorder, irreversible ones, pseudo-first-order and pseudo-second-order ones based on the solution concentration (Adebowale et al. 2008). The major contribution of this study is to provide data on crystallinity and interaction with orthophosphate by kaolinites extracted from Oxisoil and bottom sediment from the Central Amazonia.

\section{EXPERIMENTAL PART}

\section{SAMPLES COLLECTION}

Samples of Oxisoil located in $\mathrm{S}^{\circ} 3^{\circ} 02^{\prime} 55.3^{\prime \prime}$ and W $60^{\circ} 04^{\prime}$ '21,4" (Kaol) and bottom sediments in $\mathrm{S} 03^{\circ} 08^{\prime} 45.9^{\prime \prime}$ and W 60 01> 05,4» (Kao2) and S $03^{\circ} 05^{\prime}$ 53.9" and W 59 58> 15» (Kao3). Soil samples were collected from 40 to $80 \mathrm{~cm}$ depths (C horizon), classified according to their physical and chemical characteristics in yellow latosols, and sediment samples were collected from the bottom of streams.

\section{PREPARATION OF FINER KAOLINITE}

To begin, all samples are dried at room temperature for a week and sieved down to a size $<0.053 \mathrm{~mm}$ to obtain finer particles from the mixed deionized water $(\sim 1 \mathrm{~L})$ with the Kao1, Kao2 and $\mathrm{KaO} 3$ at $<0.053 \mathrm{~mm}$ under shaker agitation and kept for 24 hours, according recommended by Couceiro and Santana (1999). Then, the supernatant was siphoned and the residue dried at room temperature for $120 \mathrm{~h}$ and triturated in an agate mortar. Nearly $10.00 \mathrm{~g}$ of Kao1 with $100 \mathrm{~mL}$ of hydrochloric acid $(1: 1)$ were used in the treatment for the elimination of iron oxides such as hematite and goethite, a process which lasted for about $120 \mathrm{~h}$. The separation of the residue occurred by centrifugation at 3,000 rpm (Damon/HN-SII) for $5 \mathrm{~min}$ and was washed thoroughly under manual shaking with demineralized water. About $10.00 \mathrm{~g}$ of Kao 2 and Kao3, previously treated with hydrogen peroxide (30\%), concentrated sulfuric acid and deionized water for removing organic matter receive the same separation treatment as Kao1. Aiming at maintaining the ionic equivalence among the samples, samples Kao1, Kao2 and Kao3 were kept 
through a $12 \mathrm{~h}$ period of stirring with $\mathrm{KCl} 1.0 \mathrm{~mol}$ $\mathrm{L}^{-1}$, dried at room temperature, crushed in an agate mortar and stored.

\section{MINERALOGICAL COMPOSITION}

To develop the study on the mineralogical composition of Kao1, Kao 2 and Kao3 the physical techniques XRD, FTIR and SEM were used. The XRD measurements carried out on a Shimadzu diffractometer LabX 6000 coupled to a source of $\mathrm{Cu}(\mathrm{k} \boldsymbol{\alpha})$ with $1=1.5418 \AA$, angle ranging from $5^{\circ}$ to $60^{\circ}\left(2 / \theta \mathrm{min}^{-1}\right)$, time constant at $5 \mathrm{~s}$. The Hinckley and Plançon index was determined in the program Origin 8.0. The chemical analyses were carried out by X-ray fluorescence (spectrometer Philips PW2400). Operation of the X-ray spectrometer had been automated and goniometer angles, and $\mathrm{kV}$ and $\mathrm{mA}$ for samples.

Infrared measurements were carried out on $\mathrm{KBr}$ pellet dried at $100{ }^{\circ} \mathrm{C}$ at a ratio of 1:300 using a Fourier Transform Infrared (FTIR) spectrometer (model 640 FTIR, Varian). Conditions for obtaining spectra include a resolution of $4 \mathrm{~cm}^{-1}$, scan number of 20 and a range of 4,000 to $400 \mathrm{~cm}^{-1}$. The SEM electron microscope FEI QUANTA 250 in samples with deposition of a conductive tape, coated with a layer of gold and images recorded under accelerating voltage of $20 \mathrm{kV}$, a current of $6.0 \times 10^{-}$ ${ }^{11}$ and $5 \times 10^{-7}$ torr pressure. In addition, mapping of the elements was done by the Energy Dispersive System (EDS) EDAX model.

Iron was studied as kaolinite substituent with ${ }^{57} \mathrm{Fe}$ Mössbauer spectrometer at 298 and $80 \mathrm{~K}$ used in a conventional transmission assembly and a source of ${ }^{57} \mathrm{Co} / \mathrm{Rh}$. The correction of isomer shifts used $\boldsymbol{\alpha F e}$. The data were numerically fitted with Lorentzian functions by the method of least squares, using the computer program NORMOS ${ }^{\circledR} 90$, written by R. A. Brand, Laboratorium für Physik Argewandte, Universität Duisburg, D-47048, Duisburg-Germany.
ADSORPTION STUDY USING ISOTHERMS AND KINECTS

The adsorption isotherms for Kao1, and Kao2 Kao3 were carried out in flasks by tanking standard $\mathrm{KH}_{2} \mathrm{PO}_{4}$ solution with concentration at $3 \mathrm{mg} \mathrm{L}^{-1}$ and $\mathrm{pH} \sim 4.0$, adjusted with $\mathrm{HNO}_{3}$ at $0.1 \mathrm{~mol} \mathrm{~L}^{-1}$. According to Miranda-Trevino and Coles (2003) mainly as a result of the degree of weathering in the different compounds. Nevertheless, the kaolinite structure possesses great advantages in many processes due to its high chemical stability and low expansion coefficient. As a consequence of adsorption, the kaolinite structure and the soil solution $\mathrm{pH}$ will change. To analyze the adsorption behaviour of kaolinite, $\mathrm{Pb}, \mathrm{Zn}$ and $\mathrm{Cd}$ were studied at three different concentrations (1, 2 and $3 \mathrm{mmol} / \mathrm{l}$ in $\mathrm{pH} 4.0$ value the kaolinite superficial charge is altered to positive that is ideal for anions adsorption. Each isotherm comprised kaolinite mass from 0.050 to $0.500 \mathrm{~g}$, ranging $0.05 \mathrm{~g}$ under agitation on shaker for $2 \mathrm{~h}$ and centrifugation at 3,000 rpm for $5 \mathrm{~min}$. The supernatants were filtered on Millipore cellulose ester membrane with $45 \mathrm{~mm}$ in pore diameter and $47 \mathrm{~mm}$ (Santos et al. 2007). All the adsorption isotherms developed in triplicate.

The kinetic curves for Kao1, and $\mathrm{Kao} 2 \mathrm{Kao} 3$ were carried out by the flask tanking standard $\mathrm{KH}_{2} \mathrm{PO}_{4}$ solution with concentration at $3 \mathrm{mg} \mathrm{L}^{-1}$, $\mathrm{pH} \sim 4$ adjusted with $\mathrm{HNO}_{3}$ to $0.1 \mathrm{~mol} \mathrm{~L}^{-1}$. Each kinetic curve comprised kaolinite mass of 0.30 $\mathrm{g}$ under different times of agitation. The flasks were stirred in a shaker at intervals of $10 \mathrm{~min}$ and ranged from 0 to $120 \mathrm{~min}$. After each interval, one flask was centrifuged at 3,000 rpm for $5 \mathrm{~min}$. The supernatants were filtered on Millipore cellulose ester membrane with $45 \mathrm{~mm}$ in pore diameter and $47 \mathrm{~mm}$ (Santos et al. 2007). All the kinetic curves developed in triplicate.

The $\mathrm{KH}_{2} \mathrm{PO}_{4}$ contents of the supernatants obtained in the adsorption isotherms and kinetic curves were analyzed by ultraviolet-visible 
spectrophotometry and the ammonium molybdate method at $885 \mathrm{~nm}$.

The equations of Freundlich and Lagergren pseudosecond order adjusted to the results obtained by adsorption isotherms and kinetic curves (Dotto et al. 2011, Souza and Santana 2014):

1. Freundlich equation

$$
q_{e}=k_{f} C_{e}^{1 / n}
$$

Where is amount of phosphorus adsorbed, $C_{e}$ is equilibrium concentration of phosphorus in solution, $k_{f}$ and $\mathrm{n}$ are empirical constants.

2. Lagergren equation

$$
\log _{10}\left(q_{e}-q\right)=\log _{10} q_{e}-k_{l} t / 2,303
$$

Where $\mathrm{q}_{\mathrm{e}}$ and $\mathrm{q}$ are phosphorus concentrations adsorbed in equilibrium in time $\mathrm{t}$ respectively, $\mathrm{kl}$ is the adsorption velocity constant.

\section{RESULTS AND DISCUSSION}

Table I shows that the $\mathrm{SiO}_{2}$ and $\mathrm{Al}_{2} \mathrm{O}_{3}$ contents determined in the Kao1, Kao2, and Kao3 are very different from theoretical values: $46.5 \%-\mathrm{SiO}_{2}$ and $39.5 \%-\mathrm{Al}_{2} \mathrm{O}_{3}$ (Aranha et al. 2010). This difference is explained by the high level weathering Amazonian region condition. Additionally, $\mathrm{Fe}_{2} \mathrm{O}_{3}$, $\mathrm{TiO}_{2}$, and in minor proportion, $\mathrm{MgO}$, and $\mathrm{CaO}$ were identified. The literature shows that mineral impurities such as quartz, anatase, rutile, pyrite, limonite, feldspar, mica, montmorillonite, and various iron and titanium oxides in kaolinites are usually found. Si and Al, in the form of hydroxides, can apparently occur as coatings on the kaolinite layers. In fact, the contents of $\mathrm{SiO}_{2}, \mathrm{Al}_{2} \mathrm{O}_{3}$ and $\mathrm{Fe}_{2} \mathrm{O}_{3}$ correspond to kaolinite, quartz and gibbsite (XRD not shown). The presence of $\mathrm{Fe}$ and $\mathrm{SiO}_{2} / \mathrm{Al}_{2} \mathrm{O}_{3}$ ratio indicate that $\mathrm{Kao} 1, \mathrm{Kao} 2$, and $\mathrm{Kao} 3$ can have isomorphic substitution of $\mathrm{Al}^{3+}$ by $\mathrm{Fe}^{3+}$ (Melo et al. 2002). The literature explained the $\mathrm{TiO}_{2}$ presence as an aggregate commonly found in kaolinite. The $\mathrm{TiO}_{2}$ content of kaolinite is apparently dependent on the mineral source. For example, feldspar, such as kaolinite from Manaus, has a low $\mathrm{TiO}_{2}$ content compared to a biotite schist or biotite granite source which shows a relatively high $\mathrm{TiO}_{2}$ (Weaver and Pollard 1973).

Figure 1 clearly shows that $d_{011} d_{01 \overline{1}} d_{0 \overline{11}}$ values are distinguishable for the three kaolinites. The kaolinite XRD presents $(h k l)$ reflections commonly affected by structural defects. Among such reflections, we can distinguish those wherein $\mathrm{k}$ is multiple of 3 , i.e., $\mathrm{k}=3 n(n=1,2,3, \ldots)$ and those wherein $\mathrm{k}^{1} 3 n$. The existence within pilings of defects caused by displacements and/or rotations at the plane layers explains the multiple observed $\mathrm{k}$. Therefore, the Hinckley and Liètard indices indicate that three kaolinites have important structural differences (Table II). Typically the modifications occur in $h k l$ where $\mathrm{k}^{1} 3 n(n=1,2,3, \ldots)$ suggesting loss of the crystallographic order and/or defects in the kaolinite structure caused by displacement type $\pm b / 3$ or $\pm 2 / 3$ rotations. As the proportion of defects is reduced, it suggests the existence of $k \neq 3 n$ with a profile similar to the hkl reflections (Aglietti and Porto Lopes 1986).

According to the Hinckley index, the structural disorder of kaolinite is more noticeable for Kaol and Kao2 than for Kao3. The structural disorder suggests the existence of weathering products from feldspars, which are precursors of kaolinites well and/or poorly ordered mainly along the $b$ axis. The Liètard index shows a high number of

TABLE I

Chemical composition of Kao1, Kao2 and Kao3 obtained

\begin{tabular}{|c|c|c|c|}
\hline \multirow{2}{*}{ Oxide } & Kao1 & Kao2 & Kao3 \\
\hline & \multicolumn{3}{|c|}{--------------\%--------------- } \\
\hline $\mathrm{SiO}_{2}$ & 66.4 & 53.3 & 52.2 \\
\hline $\mathrm{Al}_{2} \mathrm{O}_{3}$ & 24.7 & 35.0 & 37.0 \\
\hline $\mathrm{SiO}_{2} / \mathrm{Al}_{2} \mathrm{O}_{3}$ & 2.70 & 1.52 & 1.41 \\
\hline $\mathrm{Fe}_{2} \mathrm{O}_{3}$ & 2.3 & 5.5 & 2.3 \\
\hline $\mathrm{TiO}_{2}$ & 6.6 & 6.2 & 8.6 \\
\hline
\end{tabular}
by X-ray fluorescence. 


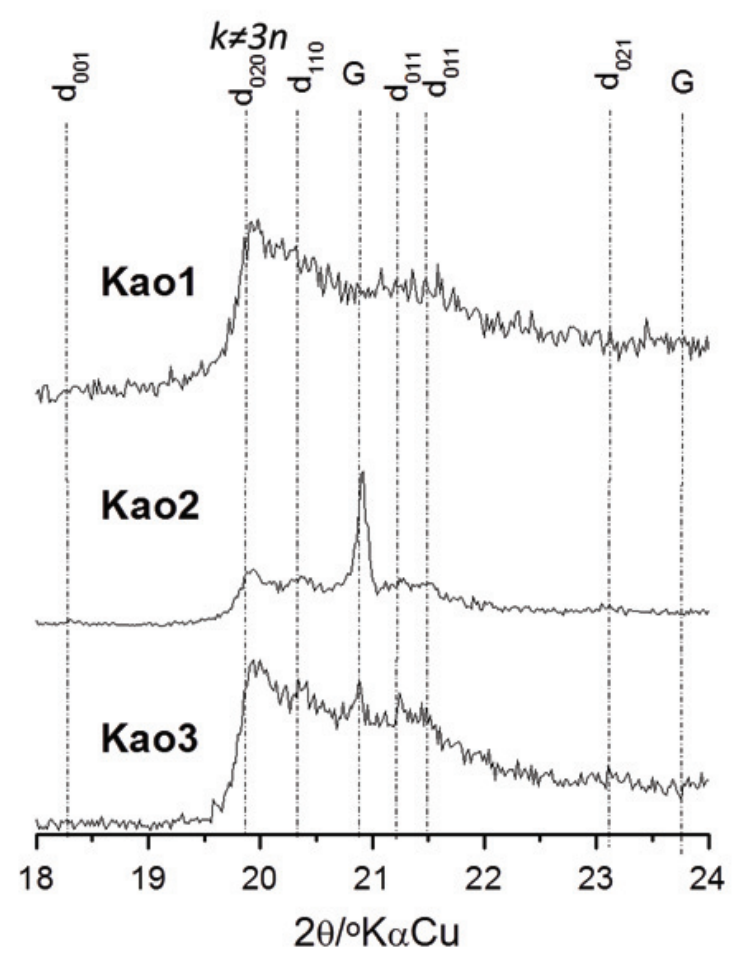

Figure 1 - X-ray diffraction patterns of kaolinites.

TABLE II

Crystallinity index of Kao1, and Kao2 Kao3.

\begin{tabular}{ccccc}
\hline Sample & Hinckley & Defect* & $\begin{array}{c}\text { Liètard } \\
\text { (R2) }\end{array}$ & Defect* \\
Kao1 & 0.549 & Mean & 0.026 & High \\
Kao2 & 0.837 & Mean & 0.871 & Mean \\
Kao3 & 0.465 & High & 0.453 & High \\
\hline \multicolumn{4}{r}{ *Categorized according to Aparicio et al. 2006. }
\end{tabular}

defects for Kao1 and $\mathrm{KaO} 3$ and average for $\mathrm{Kao} 2$ obeying the following order: Kao1 $>\mathrm{Kao} 3>\mathrm{Kao} 2$. Alterations in the kaolinite structure occur due to the isomorphic substitution by $\mathrm{Fe}^{3+}$, spaces caused by the loss of $\mathrm{Al}^{3+}$ or electronic defects (Gaite et al. 1997, Aparicio et al. 2006). The chemical analysis indicating a high amount of $\mathrm{Fe}_{2} \mathrm{O}_{3}$ a loss of about $15.0 \% \mathrm{Al}_{2} \mathrm{O}_{3}$ and an increase of $20.0 \%$ $\mathrm{SiO}_{2}$ explain the presence of iron and spaces in the kaolinite structure of Kaol as well as changes in the displacement $\pm b / 3$ and rotation $\pm 2 p / 3$.
The FTIR spectra shows absorption bands of stretching vibrational $\mathrm{OH}$ groups (internal and external) present in the octahedral sites (Figure 2). At $3619-3621 \mathrm{~cm}^{-1}$ a band stretching vibrational absorption parallel to the $a b$ plane is observed, i.e., in the common plane of apical oxygen of the tetrahedral sheet. The vibrational absorption bands in Kao1, Kao2, and $\mathrm{Kao} 3$ indicates a similarity to the internal $\mathrm{OH}$ groups of the three kaolinites. The presence of an absorption band at $3696 \mathrm{~cm}^{-1}$ characterizes perpendicular vibrational mode typical of the octahedral layer. It suggests a preservation of the $\mathrm{OH}$ groups from the kaolinite surface in all samples. It shows Kao1, Kao2, and Kao3 having their hydrogens linked with oxygen atoms bound to octahedral layer surface without considerable change. The vibrational mode of $\mathrm{O}-\mathrm{H}$ bound to the atom of aluminum octahedral layer confirms what we had imagined.

However, the relationship of intensity of the stretch bands 3619-3621 and $3696 \mathrm{~cm}-1$ indicates different levels of pleochroism for Kao1, Kao2, and Kao3. Kao1 presents an inversion of the intensity of the bands, i.e., absence of pleochroism caused due to rotation $\pm 2 \pi / 3$, as shown in the XRD (Aglietti and Porto Lopez 1986). The ratio of intensity between the bands at 795 and $755 \mathrm{~cm}-1$ also demonstrates loss of pleochroism. According to Deng et al. (2002), it occurs because of the particle size reduction. The absence of the 3652 cm-1 band in Kao3 shows vibrations directly related to weak hydrogen bonds typical of kaolinite of low crystallinity and the three vibrational modes remaining indicate $\mathrm{OH}$ groups coupled with moments of transition in the d001 plane (Farmer 2000, Frost et al. 2001). The shape of the band that corresponds to the angular-displacement vibration in $938 \mathrm{~cm}^{-1}$ indicates a kaolinite with a low number of hydrogen bonds in octahedral surface (Figure 2). The absorption band in $914 \mathrm{~cm}^{-1}$ relative to the angular-displacement vibration corresponds to the aluminol (Al-O-H) group. Furthermore, the $\mathrm{O}-\mathrm{H}$ 


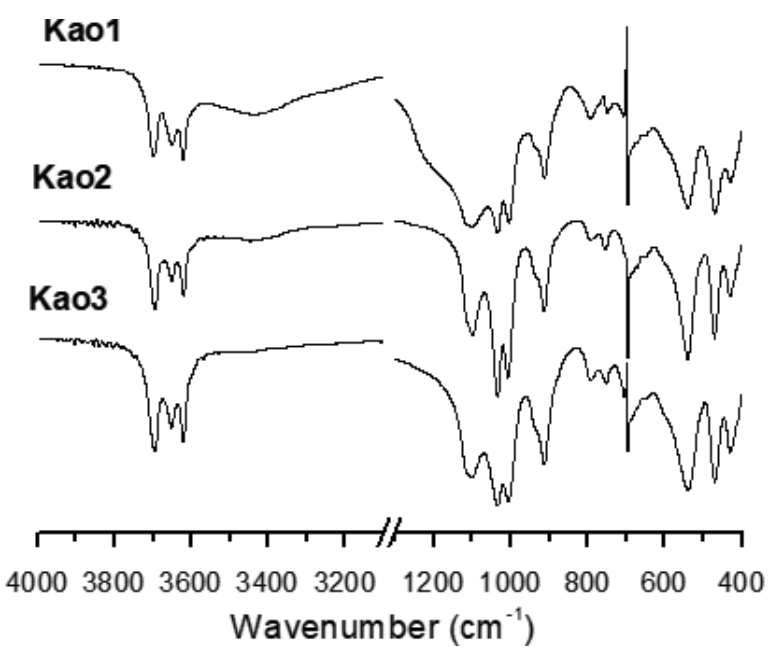

Figure 2 - FT-IR of the samples.

bond is unchanged for octahedral and tetrahedral sheets layers indicated by the stretching band at $3619-3621 \mathrm{~cm}^{-1}$.

In the $1010 \mathrm{~cm}^{-1}$ region, the Kao1, Kao2, and $\mathrm{Kao} 3$ are varied by absorption band of $\mathrm{Si}-\mathrm{O}$ stretch suggesting different particle sizes as well as low crystallinity (Shoval et al. 1999). It is interesting to note that the concentrations of $\mathrm{SiO}_{2}$ and $\mathrm{Al}_{2} \mathrm{O}_{3}$ are different for Kao2 and Kao3, which suggests two types of kaolinite. The relative intensities of 468 (band angular vibration of Si-O) and $539 \mathrm{~cm}^{-1}$ (band angular vibration of $\mathrm{Si}-\mathrm{O}-\mathrm{Si}$ ) showed that $\mathrm{Kao} 1$ has small amounts of $\mathrm{Al}_{2} \mathrm{O}_{3}$ suggesting the existence of isomorphic substitution in the octahedral site. Therefore, the changes in the vibrational modes detected by the loss of pleochroism, differences in the angular vibration suggest that kaol has changed its crystalline structure due to isomorphic substitution.

The SEM of Kao1, Kao2 and Kao3 are typical of kaolinite (Figure 3). Kao1 presents groups and stacks in the form of pilasters and crystals in the form of lamellae. This structure called booklet with pictures and cylindrical vacancies, produces porosities in the kaolinite lattices while Kao2 presents rod-shaped forms of "stalactite", presenting better crystallinity. Kao3 shows strong placoid sheets, vertical growth toward the crystallographic c axis, showing mineral habit is not well defined. The mapping elements by EDS Kao1, $\mathrm{Kao} 2$ and Kao 3 revealed that the predominant elements are $\mathrm{Si}, \mathrm{Al}, \mathrm{O}, \mathrm{Fe}$ and Ti. The SEM shows that the morphology and particle sizes from Kao1, Kao2 Kao3 have several levels.

Mössbauer parameters and spectra at $298 \mathrm{~K}$ clearly show that Kao1, and Kao2 Kao3 possesses paramagnetic $\mathrm{Fe}^{3+}$, suggesting isomorphic substitution of $\mathrm{Fe}^{3+}$ by $\mathrm{Al}^{3+}$ in the octahedral sites (Figure 4 and Table III). Furthermore, the widest line $\left(\mathrm{G}=0.62\right.$ and $\left.0.71 \mathrm{~mm} \mathrm{~s}^{-1}\right)$ indicate the presence of a triclinic kaolinite with layers influenced by differences in layer stacking of polytypes as well as by degree of layer stacking order. (Komusinski et al. 1981).

Although the Mössbauer spectra showed that the majority of kaolinites contain divalent iron in octahedral coordination, there were no values of $\mathrm{d}=1.130 \pm 0.050 \mathrm{~mm} \mathrm{~s}^{-1}$ for the $\mathrm{Fe}^{2+}$ substituted octahedral site. In turn, the orientation of the hydroxyl groups of octahedral sheets is determined by the stretching layer as well as by the symmetry of the crystal field in which the $\mathrm{Fe}^{3+}$ is located.

Mössbauer parameters found for $\mathrm{Fe}^{3+}$ are characteristic of isomorphic substitution in position cis and trans-OH (Taneja and Raj 1993). Therefore, it is not only the structural differences of kaolinites caused by defects and different octahedral shapes (Heller-Kallai and Rozenson 1981). Actually, the paramagnetic behavior observed reveals that kaolinite contains structural defects in its crystal lattice due to isomorphic substitution by $\mathrm{Fe}^{3+}$, causing disorder and changing the spin-spin interaction making the paramagnetic (Gaite et al. 1997). Furthermore, the Mössbauer spectra are distinguishable showing polytypic modifications of kaolinite with different line-widths. The presence of $\mathrm{Fe}^{3+}$ forming $\mathrm{OH}$-cis and $\mathrm{OH}$-trans points out trapped hole centers in kaolinite structure, 

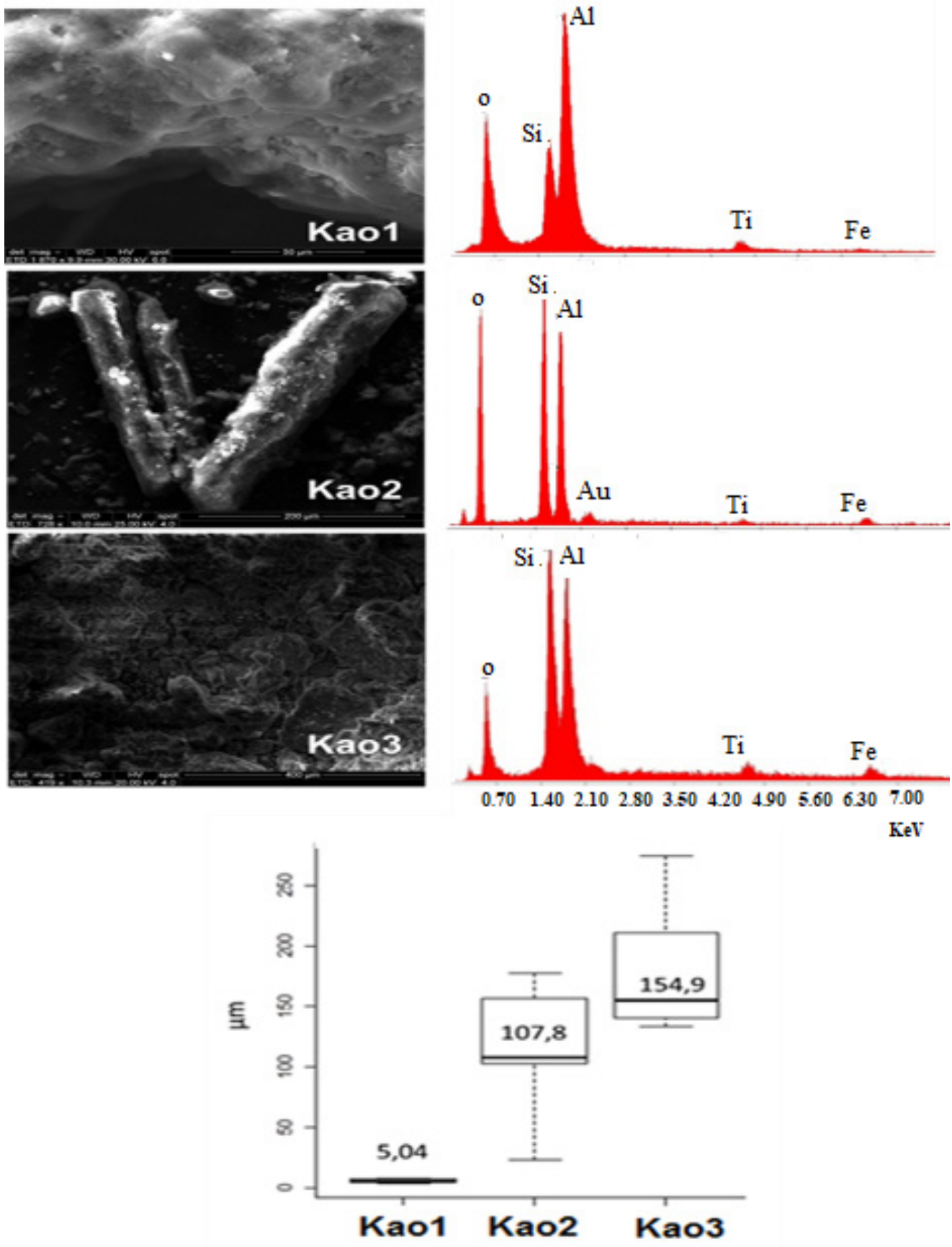

Figure 3 - Secondary electron images of scanning electron microscopy and EDS spectrum of the Kao1 and Kao2 Kao3 samples. 
trapping locus for electron holes (holes), i.e., the substitution of $\mathrm{Al}^{3+}$ by $\mathrm{Fe}^{3+}$ forms a positive moiety of the trapped separated charge pair produced by electronic excitation (Coyne and Summers 1991). According to Sato et al. (2004), the holes in kaolinites occur in B- or C-sites which explains the formation of the chiral structure.

The relative areas of the fitted Mössbauer spectra indicate that isomorphic substitution is greater in the octahedral site in cis position, following this order of reason AR-cis/AR-trans: Kao1 (10.5) > Kao2 (4.0) > Kao3 (2.8). Mössbauer spectra d and D (e) of paramagnetic $\mathrm{Fe}^{3+}$ from silicate and/or iron oxides, not identified by previous physical techniques. The $80 \mathrm{~K}$ spectra demonstrate that only Kao2 shows low among iron oxides as well as a low supermagnetism effect (Rozenson et al. 1982). The Mössbauer parameters $\left(\mathrm{d}, \mathrm{D} / \mathrm{e}\right.$ e $\left.\mathrm{B}_{\mathrm{hf}}\right)$ are typical of hematite $\left(\alpha-\mathrm{Fe}_{2} \mathrm{O}_{3}\right)$ and goethite $(\alpha-\mathrm{FeOOH})$.

The study of the crystal structure observed for $\mathrm{Kao} 1, \mathrm{Kao} 2$ and $\mathrm{Kao} 3$ indicate a relation among the degree of substitution of $\mathrm{Fe}^{3+}$ at octahedral sites, characterized by the presence of $\mathrm{Fe}^{3+}$ at positions cis/trans-OH causing defects in the crystal structure of kaolinite, changing the crystalline arrangement and size of the average particle. Physical measurements reveal a larger amount of octahedrons consisting of $\mathrm{Fe}^{3+}$ at the position cis to Kao1, differing considerably in relation to $\mathrm{Kao} 2$ and Kao3.

The adsorption process of phosphorus is characterized by having the parameters of adjustments to the Freundlich isotherms values $\mathrm{R}^{2} \sim 0.99$ indicating that adsorption occurs in the presence of heterogeneous surfaces on octahedral sites (Table IV). The negative $n$ values suggest low

TABLE III

Mössbauer parameters at 298 and $80 \mathrm{~K}$.

\begin{tabular}{|c|c|c|c|c|c|}
\hline Samples & Site $\left({ }^{57} \mathrm{Fe}\right)$ & $\mathrm{d}\left(\mathrm{mm} \mathrm{s}^{-1}\right)$ & D. e $\left(\mathrm{mm} \mathrm{s}^{-1}\right)$ & $\mathrm{B}_{\mathrm{hf}}(\mathrm{T})$ & RA (\%) \\
\hline \multicolumn{6}{|c|}{$298 \mathrm{~K}$} \\
\hline \multirow{2}{*}{ Kao1 } & $\mathrm{Fe}^{3+} c i s$ & $0.355(5)$ & $0.529(9)$ & 0.0 & $91.3(2)$ \\
\hline & $\mathrm{Fe}^{3+}$ trans & $0.38(5)$ & $1.6(1)$ & 0.0 & $8.7(2)$ \\
\hline \multirow{2}{*}{$\mathrm{Kao} 2$} & $\mathrm{Fe}^{3+} c i s$ & $0.351(2)$ & $0.511(5)$ & 0.0 & $80(2)$ \\
\hline & $\mathrm{Fe}^{3+}$ trans & $0.37(1)$ & $0.93(4)$ & 0.0 & $20(2)$ \\
\hline \multirow{3}{*}{ Kao3 } & $\mathrm{Fe}^{3+} c i s$ & $0.355(3)$ & $0.474(9)$ & 0.0 & $69(2)$ \\
\hline & $\mathrm{Fe}^{3+}$ trans & $0.36(1)$ & $0.93(3)$ & 0.0 & $25(2)$ \\
\hline & $\mathrm{Fe}^{3+}$ & $0.37(3)$ & $2.11(6)$ & ----- & $6.9(8)$ \\
\hline \multicolumn{6}{|c|}{$80 \mathrm{~K}$} \\
\hline \multirow{2}{*}{ Kaol } & $\mathrm{Fe}^{3+} c i s$ & $0.455(7)$ & $0.59(1)$ & 0.0 & $89(1)$ \\
\hline & $\mathrm{Fe}^{3+}$ trans & $0.69(3)$ & $2.39(7)$ & 0.0 & 11(1) \\
\hline \multirow{4}{*}{ Kao2 } & $\mathrm{Fe}^{3+}\left(\alpha-\mathrm{Fe}_{2} \mathrm{O}_{3}\right)$ & $0.48(2)$ & $-0.20(2)$ & $52.0(1)$ & $8.0(8)$ \\
\hline & $\mathrm{Fe}^{3+}(\alpha-\mathrm{FeOOH})$ & $0.45(1)$ & $-0.23(2)$ & $46.28(8)$ & $30(1)$ \\
\hline & $\mathrm{Fe}^{3+} c i s$ & $0.456(4)$ & $0.550(6)$ & 0.0 & $44.8(5)$ \\
\hline & $\mathrm{Fe}^{3+}$ trans & $0.56(1)$ & $1.87(2)$ & 0.0 & $16.9(6)$ \\
\hline \multirow{3}{*}{ Kao3 } & $\mathrm{Fe}^{3+} c i s$ & $0.463(7)$ & $0.59(1)$ & 0.0 & $80(2)$ \\
\hline & $\mathrm{Fe}^{3+}$ trans & $0.60(3)$ & $1.65(5)(3)$ & 0.0 & $11(2)$ \\
\hline & $\mathrm{Fe}^{3+}$ & $0.47(4)$ & $2.67(9)$ & 0.0 & $9(2)$ \\
\hline
\end{tabular}

$d=$ aFe isomer shift; $e=$ isomer quadrupole splitting; $D=$ Quadrupole; $B_{\mathrm{hf}=}$ hyperfine magnetic field; $R A=$ relative area. 


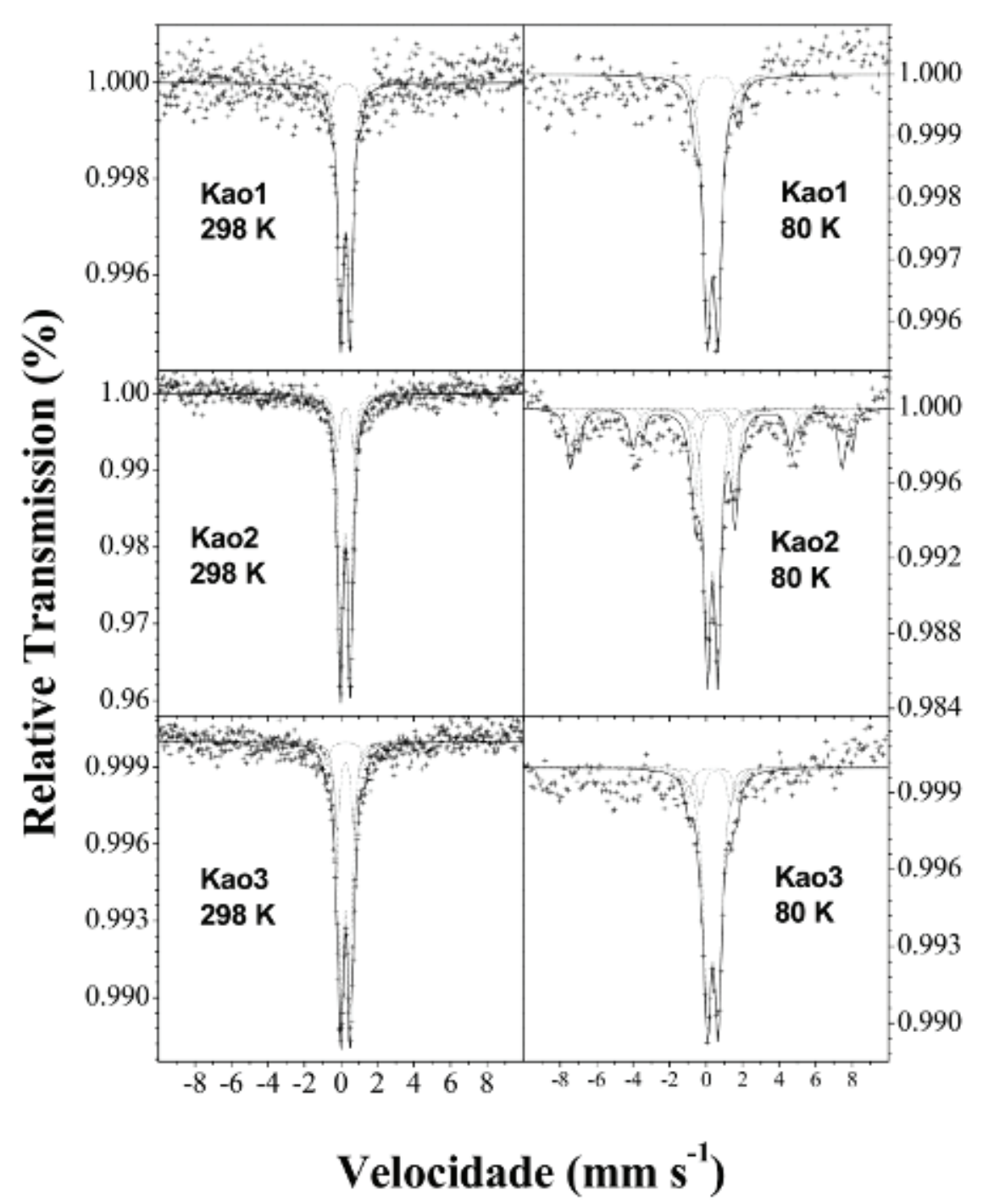

Figure 4 - Mössbauer spectra at $298 \mathrm{~K}$ and $80 \mathrm{~K}$ of the samples.

adsorption capacity of orthophosphate adsorption for all samples. It is explained by physical measurements mainly by substitution of $\mathrm{Fe}^{3+}$, responsible for the differentiation of cis, and trans octahedral sites. The adsorption capacity obeys the following order Kao1 $>\mathrm{Kao} 2>\mathrm{Kao} 3$. Largegren parameters (equation pseudo-second-order) clearly show that Kaol retains faster orthophosphate on its surface. The increase in the substitution of $\mathrm{Fe}^{3+}$ cis in the octahedral sites explains the retention of orthophosphate by Kao1 than Kao2 and Kao3. These findings reveal that the iron in the kaolinite structure contributed with their chemical nature and high specific area as an important role in the transport and the removal of orthophosphate.

\section{CONCLUSIONS}

The mineral composition comprised kaolinite, quartz, gibbsite and goethite. As major element the EDS spectra and X-ray fluorescence showed the prevalence of $\mathrm{Al}$ and $\mathrm{Si}$.

The presence of goethite indicates that Kaol and Kao3 are not as weathering as Kao2. XRD 
TABLE IV

Parameters of Freundlich adsorption kinetics and Largegren (equation pseudo-second-order).

\begin{tabular}{|c|c|c|c|c|c|}
\hline \multicolumn{6}{|c|}{ Freundlich } \\
\hline Amostra & $\mathrm{K}_{\mathrm{f}}$ & $\mathrm{n}$ & & $\mathrm{R}^{2}$ & $\log q_{e}=B+A X$ \\
\hline Kaol & 17.333 & -1.160 & & 0.99 & $\begin{array}{c}1.239-0.984 \\
\log \mathrm{m}\end{array}$ \\
\hline Kao2 & 17.954 & -1.321 & & 0.99 & $\begin{array}{l}1.250-0.768 \\
\quad \log m\end{array}$ \\
\hline Kao3 & 18.192 & -0.989 & & 0.99 & $\begin{array}{c}1.260-1.010 \\
\log \mathrm{m}\end{array}$ \\
\hline \multicolumn{6}{|c|}{ Largegren } \\
\hline & $\mathrm{q}_{\mathrm{e}}$ & $\mathrm{k}_{2}$ & $\mathrm{H}$ & & $\mathrm{t} / \mathrm{q}_{\mathrm{t}}$ \\
\hline Kaol & 0.108 & -2.534 & -0.030 & 0.97 & $-33.803+9.256 t$ \\
\hline Kao2 & 0.174 & -10.313 & -0.310 & 0.99 & $-3.218+5.761$ \\
\hline Kao3 & 0.183 & -46.021 & -1.550 & 0.99 & $-0.644+5.443$ \\
\hline
\end{tabular}

summarizes Kao 1 and Kao2 as poorly crystallized/ ordering, while kao2 as crystallized/ordering. As a result of average particle reduction, FTIR showed a higher inversion of the vibration bands relative to the hydroxyl groups in the range of $3619-3696 \mathrm{~cm}^{-1}$ and 795 and $755 \mathrm{~cm}^{-1}$ suggesting a natural loss of pleochroism of the Kao1 samples.

SEM Images showed that Kao2 is wellcrystallized while Kao1 and Kao3, poorly crystallized. These results explain the values of the Hinckley, and Liétard indices obtained. Generally, samples substituted by $\mathrm{Fe}^{3+}$ form octahedral sites in the position cis-OH and trans-OH. The adsorption isotherms and kinetics, fitted by Freundlich and Largegren equations confirm the existence of heteronuclear sites on kaolinite surfaces

The $\mathrm{Fe}^{3+}$-isomorphic substitution alters the magnetic properties of the kaolinite to paramagnetic according to the Mössbauer spectroscopy. The number of $\mathrm{Fe}^{3+}-\mathrm{OH}$-cis determines the capacity to adsorb orthophosphate.

\section{REFERENCES}

ADEBOWALE KO, UNUABONAH EI AND OLUOWOLABI BI. 2008. Kinetic and thermodynamic aspects of the adsorption of $\mathrm{Pb}^{2+}$ and $\mathrm{Cd}^{2+}$ ions on tripolyphosphatemodified kaolinite clay. Chem Eng J 136: 99-107.
AGLIETTI EF AND PORTO LOPEZ EP. 1986. Mechanochemical effects in kaolinite grinding. ii. Structural aspects. Int J Miner Process 16: 135-146.

APARICIO P, GALÁN E AND FERRELL RE. 2006. A new kaolinite order index based on XRD profile fitting. Clay Miner 41(4): 811-817.

ARANHA DA PAZ SP, ANGÉLICA RS AND DE FREITAS NEVES R. 2010. Síntese hidrotermal de sodalita básica a partir de um rejeito de caulim termicamente ativado. Quim Nova 33(3): 579-583.

BALAN E, ALLARD T, BOIZOT B, GUILLAUME M AND MULLER JP. 2000. Quantitative measurement of paramagnetic $\mathrm{Fe}^{3+}$ in kaolinite. Clay Clay Miner 48(4): 439-445.

CORRÊA MM, KER JC, BARRÓN V, TORRENT J, CURI N AND TORRES TCP. 2008. Caracterização física, química, mineralógica e micromorfológica de horizontes coesos e fragipãs de solos vermelhos e amarelos do ambiente tabauleiros costeiros. R Bras Ci Solo 32: 297-313.

COUCEIRO PRC AND SANTANA GP. 1999. Caulinita em solo da Amazônia: Caracterização e Permutabilidade. Acta Amaz 29: 267-275.

COYNE LM AND SUMMERS DP. 1991. Surface activation of air oxidation of hydrazine on kaolinite. 2. Consideration of oxidizing/reducing entities in relationship to other compositional, structural, and energetic factors. Langmuir 7(8): 1675-1688.

CUI Y AND WENG L. 2013. Arsenate and phosphate adsorption in relation to oxides composition in soils: LCD modeling. Environ Sci Technol 47(13): 7269-7276.

DENG Y, WHITE GN AND DIXON JB. 2002. Effect of Structural Stress on the Intercalation Rate of Kaolinite. J Colloid Interf Sci 250(2): 379-393. 
DIXON JB. Kaolin and serpentine group minerals. 1989. In: Dixon JB and Weed SB (Eds), Minerals in Soil Environments, $2^{\text {nd }}$ ed., Madison: Soil Science Society of America, p. 467-525.

DOTTO GL, VIEIRA MLG, GONÇALVES JO AND PINTO LAA. 2011. Remoção dos corantes azul brilhante, amarelo crepúsculo e amarelo tartrazina de soluções aquosas utilizando carvão ativado, terra ativada, terra diatomácea, quitina e quitosana: estudos de equilíbrio e termodinâmica. Quim Nova 34(7): 1193-1199.

FARMER VC. 2000. Transverse and longitudinal crystal modes associated with $\mathrm{OH}$ stretching vibrations in single crystals of kaolinite and dickite. Spectrochimica Acta A 56: 927-930.

FROST RL, KRISTÓF J, HORVÁTH E AND KLOPROGGE JT. 2001. The Modification of Hydroxyl Surfaces of Formamide-Intercalated Kaolinites Synthesized by Controlled Rate Thermal Analysis. J Colloid Interf Sci 239(1): 126-133.

GAITE JM, ERMAKOFF P, ALLARD T AND MULLER JP. 1997. Paramagnetic $\mathrm{Fe}^{3+}$ : a sensitive probe for disorder in kaolinite. Clay Clay Miner 45(4): 496-505.

HELLER-KALLAI L AND ROZENSON I. 1981. The use of Mössbauer spectroscopy of iron in clay mineralogy. Phys Chem Miner 7: 223-238.

KAMIYANGO MW, MASAMBA WRL, SAJIDU SMI AND FABIANO E. 2009. Phosphate removal from aqueous solutions using kaolinite obtained from Linthipe, Malawi. Phys Chem Earth 34(13-16): 850-856.

KHAWMEE K, SUDDHIPRAKARN A, KHEORUENROMNE I AND SHING B. 2013. Surface charge properties of kaolinite from Thai soils. Geoderma 192: 120-131.

KOMUSINSKI J, STOCH L AND DUBIEL SM. 1981. Application of electron paramagnetic resonance and Mössbauer spectroscopy In The investigation of kaolinitegroup minerals. Clay Clay Miner 29(1): 23-30.

MELO VF, SCHAEFER CEGR, SINGH B, NOVAIS RF AND FONTES MPF. 2002. Propriedades químicas e cristalográficas da caulinita e dos óxidos de ferro em sedimentos do grupo Barreiras no município de Aracruz, Estado do Espírito Santo. R Bras Ci Solo 26: 53-64.

MIRANDA-TREVINO JC AND COLES CA. 2003. Kaolinite properties, structure and influence of metal retention on pH. Appl Clay Sci 23(1-4): 133-139.

REHIM MHA, YOUSSEF AM AND ESSAWY HA. 2010. Hybridization of kaolinite by consecutive intercalation: Preparation and characterization of hyperbranched poly(amidoamine)-kaolinite nanocomposites. Mat Chem Phys 119(3): 546-552.

ROZENSON I, SPIRO B AND ZAK I. 1982. Transformation of iron-bearing kaolinite to iron-free kaolinite, goethite, and hematite. Clay Clay Miner 30(3): 207-214.

SANTOS MDLS, MUNIZ K, FEITOSA FAN AND BARROS NETO B. 2007. Estudo das diferentes formas de fósforo nas águas da plataforma continental do Amazonas. Quim Nova 30(3): 569-573.

SATO H, ONO K, JOHNSTON CT AND YAMAGISHI A. 2004. First-principle study of polytype structures of $1: 1$ dioctahedral phyllosilicates. Am Mineral 11-12: 15811585.

SHOVAL S, YARIV S, MICHAELIAN KH AND GÉRARD PANCZER L. 1999. A Fifth OH-Stretching Band in IR Spectra of Kaolinites. J Colloid Interf Sci 212(2): 523-529.

SOUZA WB AND SANTANA GP. 2014. Mineralogy, zinc kinetic adsorption and sequential extraction of contaminated soil in Manaus, Amazon. Ciênc Rural 44(5): 788-793.

TANEJA SP AND RAJ D. 1993. Mössbauer and X-ray studies of soils. Nucl Instrum Methods Phys Res B76: 233-235.

TOMBÁCZ E, NYILAS T, LIBOR Z AND CSANAKI C. 2004. Surface charge heterogeneity and aggregation of clay lamellae in aqueous suspensions. Prog Coll Pol Sci 125: 206-215.

WEAVER CE AND POLLARD LD. 1973. The chemistry of clay minerals. Amsterdam: Elsevier Science, p. 212.

WEI S, TAN WF, LIU F, ZHAO W AND WENG LP. 2014. Surface properties and phosphate adsorption of binary systems containing goethite and kaolinite. Geoderma 213: 478-484. 